\title{
The susceptibility of never-dried and freeze-dried bacterial cellulose towards esterification with organic acid
}

\author{
Koon-Yang Lee and Alexander Bismarck* \\ Polymer and Composites Engineering (PaCE) Group \\ Department of Chemical Engineering, Imperial College London, South Kensington Campus, London SW7 2AZ, UK \\ *Corresponding author: Tel: +44 (0)20 75945578; Fax: +44 (0)20 7594 5638; \\ E-mail address: a.bismarck@imperial.ac.uk
}

\begin{abstract}
The susceptibility of (i) never-dried and (ii) freeze-dried bacterial cellulose (BC) towards organic acid esterification is reported in this work. When never-dried BC (BC which was solvent exchanged from water through methanol into pyridine) was modified with hexanoic acid, it was found that the degree of substitution (DS) was significantly lower than that of hexanoic acid modified freeze-dried BC. The crystallinity of freeze-dried BC hexanoate was found to be significantly lower compared to neat $\mathrm{BC}$ and never-dried $\mathrm{BC}$ hexanoate. This result, along with the high DS indicates that significant bulk modification occurred during the esterification of freeze-dried BC. Such results were not observed for never-dried BC hexanoate. All these evidence point towards to fact that freeze-dried $\mathrm{BC}$ was more susceptible to organic acid esterification compared to never-dried BC. A few hypotheses were explored to explain the observed behaviour and further investigated to elucidate our observation; the effect of residual water in cellulose, the accessibility of hydroxyl groups and the crystal structure of never-dried and freeze-dried $\mathrm{BC}$ on the susceptibility of cellulose fibrils to esterification, respectively. However, the investigation of these hypotheses raised more questions and we are still left with the main question; why do BC nanofibres behave differently when modifying freeze-dried BC or never-dried BC?
\end{abstract}

Keywords: Esterification, organic acids, bacterial cellulose, freeze-dried state, never-dried state 


\section{Introduction}

Cellulose is used in numerous industries; the pulp and paper industry (Sczostak 2009), the pharmaceutical and cosmetic industry (Klemm et al. 2005) and more recently as reinforcement for polymers (Eichhorn et al. 2010; Habibi et al. 2010; Gardner et al. 2008; Blaker et al. 2011). Due to the rapid advancement and interest in nanotechnology, significant effort has been poured into the utilisation and isolation of nano-sized cellulose to produce nanocellulose for various applications. Nanocellulose can be obtained via two approaches; top-down or bottom-up. The top-down approach involves the disintegration of plant cellulose, such as wood fibres, using high shear forces (Turbak et al. 1983; Herrick et al. 1983). The bottom-up approach, on the other hand, utilises the biosynthesis of cellulose by bacteria, such as from the Acetobacter species (Brown 1886).

Although nanocellulose can be produced using the two approaches, the quality of bacterial cellulose (BC) was found to be superior over wood-derived nanocellulose (Klemm et al. 2009). This can be attributed to the high purity of BC. Additionally, no further processing is required to obtain nano-sized cellulose. In addition to this, BC possesses a high degree of crystallinity of up to $90 \%$ (Czaja et al. 2004). Hsieh et al. (Hsieh et al. 2008) determined the mechanical properties of a single BC nanofibre using Raman spectroscopy. The authors estimated that a single BC nanofibre possesses a Young's modulus of $114 \mathrm{GPa}$. Cellulose crystals possess a theoretical Young's modulus of between 130 and $160 \mathrm{GPa}$ depending on the crystal form (Eichhorn and Davies 2006; Reiling and Brickmann 1995). These properties are highly favourable for the utilisation of nanocellulose as filler for polymers. However, the hydrophilic nature of cellulose often resulted in poor interfacial adhesion between the cellulose and hydrophobic polymer matrices (Pommet et al. 2008; Siro and Plackett 2010), such as polypropylene and polylactic acid. Surface modification of nanocellulose is often performed to improve the compatibility and, therefore, the stress transfer between the cellulose and the matrix to produce nanocomposites with improvements in both modulus and strength (Lee et al. 2009; de Menezes et al. 2009; Ly et al. 2010; Blaker et al. 2011).

$\mathrm{BC}$ can be modified by introduction of acetate functional groups, i.e. by reaction with acetic acid, in toluene using perchloric acid as catalyst to produce BC with hydrophobic characteristics (Kim et al. 2002; Ifuku et al. 2007). Nanocellulose modification is typically conducted using acetic anhydride (Tingaut et al. 2010). Acetic acid has also been used for nanocellulose modification 
(Ifuku et al. 2007; Kim et al. 2002). These modifications are limited to synthesis of short chain cellulose esters of alkanoic acids. In order to modify nanocellulose with long-chain aliphatic acids, a two-step reaction has to be used to first produce long chain aliphatic anhydride moieties using trifluoroacetic anhydride, followed by cellulose modification (Heinze et al. 2006). The use of pyridine along with long chain aliphatic carboxylic acids and acid chlorides allowed us to activate the long chain carboxylic acids and produce nanocellulose modified with long chain aliphatic moieties, such as cellulose hexanoate or dodecanoate (Lee et al. 2009).

The chemical modification of BC presents an interesting scenario. Since BC is produced by the biosynthesis of bacteria in an aqueous culture medium, BC stays hydrated and so is never-dried. We have previous reported the successful surface-only modification of never-dried $\mathrm{BC}$ with long chain organic acids (Lee et al. 2009; Lee et al. 2011). The procedure we followed involved the solvent exchange of never-dried $\mathrm{BC}$ from water through methanol into pyridine. Attempts were made to reduce the laborious solvent exchange step by freeze-drying $\mathrm{BC}$ from water and disperse freeze-dried $\mathrm{BC}$, which does not hornify, directly into pyridine to carry out the same esterification with organic acids. To our surprise we observed that freeze-dried $\mathrm{BC}$ is much more susceptible towards esterification with organic acid compared to never-dried BC. Possible hypotheses of the observed susceptibility of freeze-dried $\mathrm{BC}$ towards organic esterification are presented and have been further investigated in this study.

\section{Experimental procedure}

Materials and methods

Methanol (GPR, purity $\geq 99 \%$ ), ethanol (GPR, purity $\geq 99.7 \%$ ), benzene (analaR NORAMPUR, purity $\geq 99.9 \%$ ) and pyridine (analaR NORAMPUR, purity $\geq 99.7 \%$ ) were purchased from VWR. Hexanoic acid (Aldrich, purity $\geq 99 \%$ ), $p$-toulenesulfonyl chloride (Aldrich, purity $\geq$ 99\%), dimethyl carbonate (Aldrich reagent plus, purity $\geq 99 \%$ ), deuterium oxide (Aldrich, purity $\geq 99.99$ atom\% D), cellulose acetate (Aldrich, $39.7 \mathrm{wt} \%$ acetyl content) and cellulose triacetate (Aldrich, 43-49 wt $\%$ acetyl content) were purchased from Sigma-Aldrich. Sodium hydroxide (purum grade, pellets) was purchased from Acros Organics. All the materials were used as received without further purification. $\mathrm{BC}$ was extracted and purified from commercially available Nata-de-coco (CHAOKOH gel in syrup, Ampol Food Processing Ltd, Nakorn Pathom, Thailand) following previously described work (Blaker et al. 2009). 


\section{Hexanoic acid esterification of $\mathrm{BC}$}

In order to modify never-dried $\mathrm{BC}$, which was always kept in water, $2 \mathrm{~g}$ (on dry weight basis) of purified $\mathrm{BC}$ was solvent exchanged from water through methanol $\left(3 \times 600 \mathrm{~cm}^{3}\right)$ into pyridine $(2$ $\times 600 \mathrm{~cm}^{3}$ ) to ensure the complete removal of water and methanol. The mixture was homogenised using a homogeniser (Polytron PT 10-35 GT, Kinematica, $\mathrm{CH}$ ) at 20,000 rpm for at least 1 min during each solvent exchange step to completely disperse the $\mathrm{BC}$ in the solvent. $\mathrm{BC}$ was retained through centrifugation at $14,000 \mathrm{~g}$ for $15 \mathrm{~min}$. The excess solvent was decanted prior to re-dispersion in the subsequent solvent. This homogenisation/centrifugation step was repeated three times. After the second solvent exchange step into pyridine, another solvent exchange step was performed to adjust the final concentration of $\mathrm{BC}$ in pyridine to $0.5 \%\left(\mathrm{~g} \mathrm{~mL}^{-1}\right)$. This $\mathrm{BC}$ pyridine mixture was then poured into a $1 \mathrm{~L} 3$-neck round bottom flask and stirred using a magnetic stirrer. $92 \mathrm{~g}$ of $p$-toluenesulfonyl chloride was added into this BC-pyridine mixture and hexanoic acid was added at an equimolar concentration relative to $p$-toluenesulfonyl chloride into the same reaction vessel. The reaction was conducted under nitrogen flow to create an inert atmosphere for $2 \mathrm{~h}$ at $50^{\circ} \mathrm{C}$. After $2 \mathrm{~h}$, the reaction was quenched with $1.5 \mathrm{~L}$ of ethanol. The product was washed three times with $800 \mathrm{~mL}$ of ethanol using the previously described homogenisation-centrifugation steps.

In a separate experiment, never-dried $\mathrm{BC}$ was homogenised in water at a concentration of $0.4 \%\left(\mathrm{~g} \mathrm{~mL}^{-1}\right)$, flash frozen in a Petri dish and subsequently freeze-dried (Edwards Modulyo freeze dryer, West Sussex, UK). This BC is termed freeze-dried BC throughout this study. $2 \mathrm{~g}$ of freeze-dried $\mathrm{BC}$ was dispersed into $400 \mathrm{~mL}\left(0.5 \%\left(\mathrm{~g} \mathrm{~mL}^{-1}\right)\right)$ of pyridine directly in a $1 \mathrm{~L}$ 3-neck round bottom flask and the reaction was conducted as previously described. After $2 \mathrm{~h}$, the hexanoic acid modified freeze-dried $\mathrm{BC}$ was purified following the procedure described above. In order to characterise the hexanoic acid modified wet $\mathrm{BC}$ and freeze-dried $\mathrm{BC}$, they were solvent exchanged from ethanol through water into dimethyl carbonate at a concentration of $0.4 \%\left(\mathrm{~g} \mathrm{~mL}^{-}\right.$ ${ }^{1}$ ), flash frozen in a Petri dish and subsequently freeze-dried from dimethyl carbonate to obtain dry modified samples that were further characterised. The never-dried $\mathrm{BC}$ hexanoate and freezedried $\mathrm{BC}$ hexanoate are termed $\mathrm{C}_{6}$ - $\mathrm{NDBC}$ and $\mathrm{C}_{6}$ - $\mathrm{FDBC}$, respectively.

Characterisation of the modified (never-dried and freeze-dried) BC 
Attenuated Total Reflection Infrared spectroscopy (ATR-IR)

ATR-IR spectra were recorded using a Spectrum One FTIR-spectrometer (Perkin Elmer, Massachusetts, USA). The spectra were collected at a resolution of $2 \mathrm{~cm}^{-1}$, in the range of $600 \mathrm{~cm}^{-1}$ and $4000 \mathrm{~cm}^{-1}$. A total of 16 scans was used to collect each spectrum.

\section{Degree of substitution of modified $B C$}

The degree of substitution (DS) of $\mathrm{C}_{6}-\mathrm{NDBC}$ and $\mathrm{C}_{6}$-FDBC was determined using the procedure developed by Sassi and Chanzy (Sassi and Chanzy 1995); the DS was calculated based on the ATR-IR spectra using the absorption band of the pyranose ring as an internal standard at a wavenumber of $1050 \mathrm{~cm}^{-1}$. A calibration master curve was established, relating the ratio of the absorbance intensities of the carbonyl bonds $\left(1750 \mathrm{~cm}^{-1}\right)$ and pyranose ring's to the known DS for cellulose acetates and cellulose triacetates. By comparing the ratio of the intensities between $1750 \mathrm{~cm}^{-1}$ and $1050 \mathrm{~cm}^{-1}$ of $\mathrm{C}_{6}$-NDBC and $\mathrm{C}_{6}$-FDBC to the calibration master curve, the DS of the modified $\mathrm{BC}$ was obtained.

\section{Crystallography of $B C$ hexanate}

The X-ray diffraction (XRD) pattern of modified BC was obtained using a PANalytical X'Pert PRO X-ray diffractomer (PANalytical Ltd, Cambridge, UK). The diffractograms were taken from $2 \theta=10^{\circ}$ to $45^{\circ}$ at a step size of $0.02^{\circ}$ using a Ni filtered $\mathrm{Cu} \mathrm{K \alpha _{1 }}(1.541 \AA)$ as the X-ray source. Segal's method (Segal et al. 1959) was used to calculate the crystallinity of (modified) BC:

$\chi_{c}=\frac{I_{002}-I_{a m}}{I_{002}} \times 100 \%$

where $\chi_{c}$ is the crystallinity of the cellulose, $I_{002}$ and $I_{a m}$ are the intensity of the $002\left(2 \theta=22.5^{\circ}\right)$ and amorphous $\left(2 \theta=18^{\circ}\right)$ reflections, respectively. This is an empirical equation for estimating the degree of crystallinity of pure cellulose materials.

Scanning electron microscopy (SEM)

SEM was performed using a high-resolution field emission gun scanning electron microscope (LEO Gemini 1525 FEG-SEM, Oberkochen, Germany). It was used to characterise the 
morphology of $\mathrm{BC}$ nanofibres after esterification with hexanoic acid. The accelerating voltage used was $5 \mathrm{kV}$. Prior to SEM, the samples were mounted to SEM stubs using carbon tabs and coated with Cr (K550 sputter coater, Emitech Ltd, Ashford, Kent, UK) for $1 \mathrm{~min}$ at $75 \mathrm{~mA}$.

Characterisation of neat never-dried and freeze-dried BC

In order to mimic the behaviour of never-dried $\mathrm{BC}$ in pyridine prior to the hexanoic acid esterification reaction, the never-dried $\mathrm{BC}$ was solvent exchanged from water through methanol into benzene using the previously described concentration and homogenisation-centrifugation steps. Once the never-dried $\mathrm{BC}$ was dispersed in benzene, it was subsequently freeze-dried to obtain a dry sample hopefully representative of never-dried BC in pyridine. Benzene was chosen as it is structurally related to pyridine and because of its ability to be freeze-dried.

\section{Determining the residual water content of never-dried and freeze-dried $B C$}

Esterification of cellulose with carboxylic acids is a reversible reaction and the presence of water will affect the conversion of cellulose to cellulose esters. The residual water content of freezedried $\mathrm{BC}$ was determined using dynamic vapour sorption (DVS-Advantage, Surface Measurement Systems Ltd, Alperton, UK). $30 \mathrm{mg}$ of freeze-dried BC was loaded into the chamber of DVS held at $0 \%$ relative humidity (RH) for $5 \mathrm{~h}$. During this period, the mass change was measured in-situ inside the chamber. The residual water content was obtained from the difference between the initial and final mass of the sample.

The residual water content in never-dried $\mathrm{BC}$ after successive solvent exchange steps was estimated from the solvent exchange efficiency. To determine the solvent exchange efficiency, $2 \mathrm{~g}$ (on a dry weight basis) of never-dried $\mathrm{BC}$ was dispersed in $600 \mathrm{~cm}^{3}$ of methanol following the previously described homogenisation step and centrifuged at 14,000g for $15 \mathrm{~min}$ after which the supernatant was removed. The water content in this supernatant was determined using KarlFischer titration (DL32 Coulometric Titrator, Mettler Toledo, Leicester, UK). The homogenisation-centrifugation-titration step was repeated 5 times (the number of solvent exchange steps in this work). The efficiency of water removal for solvent exchange was calculated using: 
$R_{w}=\frac{W_{i+1}-W_{i}}{W_{i}} \times 100 \%$

where $R_{w}, W_{i+1}$ and $W_{i}$ are the water removal efficiency, the water content after the solvent exchange step $i+1$ and step $i$, respectively.

\section{Determining the hydroxyl group availability of never-dried and freeze-dried $B C$}

In order to study the difference between the hydroxyl group availability for the esterification reaction of the different starting $\mathrm{BC}$, a method based on hydrogen/deuterium $(\mathrm{H} / \mathrm{D})$ exchange was utilised following our previous work (Lee et al. 2011). This measurement was carried out using dynamic vapour sorption (DVS-Advantage, Surface Measurement Systems Ltd, Alperton, UK). A sample mass of approximately $30 \mathrm{mg}$ of $\mathrm{BC}$ was placed in the sample pan and the sample chamber was pre-conditioned at $0 \% \mathrm{RH}$ of deuterium oxide $\left(\mathrm{D}_{2} \mathrm{O}\right)$ for $5 \mathrm{~h}$ at room temperature to remove adsorbed water molecules. The $\mathrm{RH}$ of $\mathrm{D}_{2} \mathrm{O}$ was increased to $90 \%$ for $2 \mathrm{~h}$ to allow for the adsorption of $\mathrm{D}_{2} \mathrm{O}$ and for $\mathrm{H} / \mathrm{D}$ exchange with accessible hydroxyl groups to occur. The $\mathrm{RH}$ was then reduced to $0 \%$ for $2 \mathrm{~h}$ to allow $\mathrm{D}_{2} \mathrm{O}$ molecules to desorb. This cycle was repeated 10 times such that the H/D can occur on all accessible hydroxyl groups on BC. A short adsorptiondesorption cycle was utilised to avoid bulk sorption of $\mathrm{D}_{2} \mathrm{O}$ in to $\mathrm{BC}$, as only the accessible hydroxyl groups were of interest. After 10 adsorption-desorption cycles, the sample was postconditioned at $0 \% \mathrm{RH}$ for $5 \mathrm{~h}$ to remove any residual adsorbed $\mathrm{D}_{2} \mathrm{O}$ molecules. As deuterium is one neutron heavier than hydrogen, the mass increase after post-conditioning of $\mathrm{BC}$ was measured in-situ by an ultra-sensitive microbalance and the amount of accessible hydroxyl groups was back calculated from this mass increase.

\section{Specific surface area measurement of never-dried and freeze-dried BC}

Nitrogen adsorption/desorption isotherms were performed to determine the specific surface area of never-dried and freeze-dried BC using a surface area and porosity analyser (TriStar 3000, Micrometrics Ltd, Dunstable, UK). The specific surface area was calculated using the BrunauerEmmett-Teller (BET) equation. Prior to the measurement, the samples were degassed at $80^{\circ} \mathrm{C}$ overnight to remove adsorbed water molecules. 


\section{Allomorphs of never-dried and freeze-dried $B C$}

The different allomorphs of crystalline cellulose were evaluated using an empirical mathematical function developed by Wada et al. (2001). This mathematical function is supposed to discriminate cellulose $\mathrm{I}_{\alpha}$, which is triclinic, from cellulose $\mathrm{I}_{\beta}$, which is monoclinic, based on the XRD pattern of the cellulose of interest. The discrimination factor $\mathrm{Z}$ is related to the $\mathrm{d}$-spacings of the cellulose via:

$Z=1693 \times d_{1}-902 \times d_{2}-549$

where $Z>0$ represents $\mathrm{I}_{\alpha}$-rich cellulose and $Z<0$ represents $\mathrm{I}_{\beta}$-rich cellulose. $d_{1}(\mathrm{~nm})$ and $d_{2}$ $(\mathrm{nm})$ represent the d-spacing of the reflection planes at Bragg's angle of $14^{\circ}$ and $16^{\circ}$, respectively.

\section{Results and Discussion}

Degree of substitution of (hexanoic acid modified) BC

ATR-IR was used to study the chemical characteristics of neat and hexanoic acid modified BC. The spectra are shown in Fig. 1. The spectra were normalised to the intensity of the absorption band corresponding to the C-O-C link in cellulose molecules, which is around $1160 \mathrm{~cm}^{-1}$ (Ilharco et al. 1997). The appearance of an absorption band around $1750 \mathrm{~cm}^{-1}$ for hexanoic acid modified $\mathrm{BC}$ can be attributed to carbonyl bonds $(\mathrm{C}=\mathrm{O})$, which formed during the esterification of $\mathrm{BC}$ with hexanoic acid. Additional peaks can also be seen around $2900 \mathrm{~cm}^{-1}$, which correspond to the absorption of methyl $\left(-\mathrm{CH}_{3}\right)$ or methylene $\left(-\mathrm{CH}_{2}-\right)$ groups. It can be seen from these spectra that the intensity of $1750 \mathrm{~cm}^{-1}$ is higher when freeze-dried $\mathrm{BC}$ was used as starting material. In addition to this, the esterification of freeze-dried $\mathrm{BC}$ with hexanoic acid resulted in a significant decrease in the intensity of the hydroxyl groups $(-\mathrm{OH})$ around $3300 \mathrm{~cm}^{-1}$. When never-dried $\mathrm{BC}$ was used as the starting material for the esterification reaction, the intensity of the carbonyl absorption band was much lower than that of $\mathrm{C}_{6}$-FDBC. This is due to the higher degree of substitution when freeze-dried $\mathrm{BC}$ was used as the starting material compared to never-dried $\mathrm{BC}$ (see Table 1). 
Morphology of BC hexanoate

The morphology of BC before and after hexanoic acid esterification is shown in Fig. 2. It can be seen that neat $\mathrm{BC}$ possesses a fibrous structure, approximately $50 \mathrm{~nm}$ in diameter and several micrometres in length. When BC was modified with hexanoic acid using never-dried $\mathrm{BC}$ as the starting material $\left(\mathrm{C}_{6}-\mathrm{NDBC}\right)$, the fibrous structure of $\mathrm{BC}$ is retained (see Fig. 2). This result corroborates the low DS, high crystallinity (Table 1) and low absorbance intensity at $1750 \mathrm{~cm}^{-1}$ in the ATR-IR spectra of $\mathrm{C}_{6}$-NDBC (Fig. 1). However, when $\mathrm{BC}$ hexanate was synthesised from $\mathrm{BC}$ as starting material $\left(\mathrm{C}_{6}\right.$-FDBC), the original fibrous structure of $\mathrm{BC}$ was lost (Fig. 2 (bottom)). Instead, the modified cellulose resembles a semicrystalline cellulose ester polymer. Similar observations were also reported by (Barud et al. 2008), who produced cellulose acetate by the acetylation of BC. This observation is consistent with the high DS and intensity of carbonyl bonds in the ATR-IR spectra, which points towards significant bulk modification during the esterification reaction.

Hypotheses for the bulk modification of freeze-dried BC and surface-only modification of neverdried BC

Could the water adsorbed on starting BC material affect the equilibrium of the esterification reaction?

The esterification reaction of cellulose with a carboxylic acid is reversible with cellulose esters and water being the product of the reaction. According to Le Chatelier's principle, the removal of water from the reaction will shift the equilibrium of the reaction to favour the production of more cellulose esters. It has also been reported that the starting form of cellulose (never-dried, partially dried or fully dried) affects the dissolution of cellulose in ionic liquid as the water molecules in the never-dried cellulose reduce the solvent quality (Spinu et al. 2011). Therefore, it can be anticipated that never-dried BC should result in a higher DS, as the presence of water shifts the esterification reaction to the left, producing more cellulose esters. The estimated residual water content for both types of BC is tabulated in Table 2. It can be seen that the efficiency of water removal was much greater through solvent exchange method compared to the direct freezedrying of $\mathrm{BC}$. This can be attributed to the hydrophilic nature of $\mathrm{BC}$, which absorbs water from the atmosphere. The water removal efficiency of the solvent exchange method was found to be 
$58 \pm 14(\mathrm{wt} / \mathrm{wt}) \%$. Through solvent exchange, wet BC is thoroughly mixed with a solvent, which is miscible with water, and the liquid phase is displaced by centrifugation and then decanted. By repeating this process, the water in wet $\mathrm{BC}$ is constantly removed and reduced to a minimum. However, this result contradicts with the DS of the modified BC, which showed freeze-dried BC (with higher residual water content) underwent severe bulk modification but never-dried BC (with lower residual water content) underwent surface only modification. The reason for this observation is not clear but it implies that the presence of water is not solely responsible for the observed different behaviour of freeze-dried and never-dried BC.

Could the accessibility of hydroxyl groups be different for freeze-dried and never-dried BC?

The accessible hydroxyl groups (-OH) of both freeze-dried and never-dried BC is tabulated in Table 2. Never-dried BC and freeze-dried BC were found to possess an accessible $-\mathrm{OH}$ group availability of 1.12 and 1.24 , respectively out of a maximum of 3 . The difference in accessible $\mathrm{OH}$ groups availability is about $10 \pm 1 \%$. This difference can be attributed to the different dispersing medium (either water or benzene) when preparing $\mathrm{BC}$. Water is known to swell cellulose, exposing more cellulose -OH groups (Venkateswaran and Riemen 1965) but non-polar molecules, like benzene, have been shown to reduce the accessibility of the hydroxyl groups of cellulose (Colombo and Immerguy 1970). As a result, BC freeze-dried from water possesses more accessible hydroxyl groups. Nonetheless, 10\% more accessible hydroxyl groups of freezedried $\mathrm{BC}$ compared to never-dried BC is not significant and does not explain the observed severe modification of freeze-dried BC.

Could the exposed surface area of never-dried and freeze-dried BC affect the severity of the esterification reaction?

There is significant evidence in the literature that freeze-drying cellulose from solvents other than water results in a significant increase of the surface area of nanocellulose (Jin et al. 2004; Kuga et al. 2002; Ishida et al. 2004). Similar results were also found in this work. When BC was solvent exchanged into benzene and freeze-dried (never-dried BC), the surface area is twice as large as BC freeze-dried from water (see Table 2). This implies that the exposed surface area of neverdried BC in a solvent is higher than that of freeze-dried BC. The larger surface area in an organic solvent is a result of the low surface tension of the solvent. Merchant (Merchant 1957) observed 
that the surface area of cellulose increases with decreasing surface tension of the organic solvent in which the cellulose was dispersed in. Although no exact reason was given at the time of this work, it can be postulated that better wetting can be expected between high surface energy BC and low surface tension liquids. This results in better dispersion of cellulose fibrils in the solvent and therefore the observed high surface area in low surface tension liquids. Nonetheless, our surface area results contradict the observation of severe bulk modification of freeze-dried BC, which possesses a lower surface area.

\section{Could the crystallography of $B C$ change as a result of drying from different solvents?}

The XRD pattern of BC hexanoate is shown in Fig. 3a-b and their crystallinity calculated from the Segal's equation in Table 1. Crystallographically, BC possess a cellulose I structure (Vanderhart and Atalla 1984). The characteristic peaks shown in Fig. 3 correspond to the diffraction planes of 101, 101, 002 and 040, respectively (Freire et al. 2006). The crystallinity of $\mathrm{C}_{6}$-NDBC is in good agreement with the crystallinity of neat BC of approximately $90 \%$ (Czaja et al. 2004). This implies that the modification of never-dried BC resulted in the surface-only modification of BC (Lee et al. 2011). When freeze-dried BC was modified with hexanoic acid using identical reaction conditions, the XRD pattern of $\mathrm{C}_{6}$-FDBC showed a significant reduction the intensities of all the diffraction planes. The crystallinity of $\mathrm{C}_{6}$-FDBC dropped to only $53 \%$, which is an indication that the cellulose loses its crystal structure and becomes more amorphous. The substitution of hydroxyl groups during the esterification reaction resulted in the reduction of the hydrogen bonding density between cellulose molecules, which in turn partially destroy the crystalline structure of bacterial cellulose (Yin et al. 2007). These results are in good agreement with the ATR-IR spectra and DS of $\mathrm{C}_{6}$-FDBC shown previously, which points towards significant bulk modification of cellulose when freeze-dried $\mathrm{BC}$ was used as the starting material. Cellulose is a semi-crystalline composite of two different crystalline structures, namely $\mathrm{I}_{\alpha}$ and $\mathrm{I}_{\beta}$, respectively (Horii et al. 1987a). Cellulose $I_{\alpha}$ possesses a triclinic structure whereas $I_{\beta}$ has a monoclinic crystalline structure (Sugiyama et al. 1991). It was found that cellulose $\mathrm{I}_{\beta}$ is the more thermodynamically favourable structure and cellulose $\mathrm{I}_{\alpha}$ can readily be converted to $\mathrm{I}_{\beta}$ via routes such as hydrothermal treatment (Horii et al. 1987b). In addition to this, at equivalent hydroxyl 
group accessibility, cellulose $\mathrm{I}_{\alpha}$ was found to be more reactive towards acetylation compared to cellulose $\mathrm{I}_{\beta}$ (Sassi et al. 2000). Wada et al. (Wada et al. 2001) derived an empirical equation (see equation 3) providing the ratio of $I_{\alpha}$ to $I_{\beta}$ based on two equatorial d-spacings of cellulose and these results are tabulated in Table 2, alongside with the crystallinity and d-spacings of neverdried and freeze-dried BC. It can be seen from this table that the crystallinity of the two types of $\mathrm{BC}$ are the same $(\sim 90 \%)$, indicating that the significant bulk modification of freeze-dried BC could not be the direct result of differences in the crystallinity of BC.

The XRD patterns of never-dried and freeze-dried BC are shown Fig. 3c-d. The two diffraction peaks, $d_{l}$ and $d_{2}$, are in fact composites of $\mathrm{I}_{\alpha}$ and $\mathrm{I}_{\beta}$ reflections (Wada et al. 2001). $d_{l}$ corresponds to $\mathrm{I}_{\alpha} 100$ and $\mathrm{I}_{\beta} 110$ reflections, respectively whereas $d_{2}$ corresponds to $\mathrm{I}_{\alpha} 010$ and $\mathrm{I}_{\beta} 110$ reflections, respectively. From the calculated $d$-spacings for the two types of cellulose, the $Z$ value (which discriminates between $\mathrm{I}_{\alpha}$-rich and $\mathrm{I}_{\beta}$-rich) can be computed. Based on the calculated $Z$ value, never-dried $\mathrm{BC}$ is rich in cellulose $\mathrm{I}_{\beta}$ whereas freeze-dried $\mathrm{BC}$ is cellulose $\mathrm{I}_{\alpha}$ dominant. Combining this result with the $-\mathrm{OH}$ group accessibility of freeze-dried $\mathrm{BC}$, which is $10 \%$ higher than that of never-dried $\mathrm{BC}$, it implies that freeze-dried $\mathrm{BC}$ is more susceptible to esterification compared to never-dried BC. This is consistent with our observations. However, this raises the next question; why should $\mathrm{BC}$, which is known to be cellulose $\mathrm{I}_{\alpha}$, have a cellulose $\mathrm{I}_{\beta}$ structure when dried from an organic solvent? There was significant evidence that points towards the fact that the surface tension of dispersing medium affects the exposed surface area of cellulose (Merchant 1957; Ishida et al. 2004; Kuga et al. 2002). It was also speculated by Merchant (1957) that the crystal structure of cellulose would be different when dried from different solvents due to the difference in polarity of the solvents.

\section{Conclusions}

We observed that $\mathrm{BC}$ freeze-dried from water is more susceptible towards organic acid esterification than never-dried BC. It was found that freeze-dried BC underwent significant bulk modification with degree of substitution of 1.87 compared to never-dried $\mathrm{BC}$ of only 0.36 . The 
crystallinity of the freeze-dried BC decreased to $53 \%$ from the original value of $90 \%$ after the modification whilst the crystallinity of never-dried BC did not change significantly after modification. A few hypotheses to explain the observed behaviour were explored; the effect of residual water, accessibility of $-\mathrm{OH}$ groups and crystal structure of the cellulose, respectively. These results were found to be in disagreement with our experimental observations. Never-dried $\mathrm{BC}$, which was solvent exchanged from water through methanol into pyridine, was found to contain less residual water compared to freeze-dried BC. This implies that significant bulk modification should occur in never-dried BC as the lack of water should shift the equilibrium of the esterification reaction to the right, producing more cellulose esters. However, it was freezedried $\mathrm{BC}$, which had a higher water content, that underwent significant bulk modification. Freeze-dried $\mathrm{BC}$ was found to possess $10 \%$ more accessible $-\mathrm{OH}$ groups compared to neverdried $\mathrm{BC}$. However, $10 \%$ more $-\mathrm{OH}$ groups is very unlikely to result in an $80 \%$ increase in the degree of substitution of modified cellulose. XRD pattern show that freeze-dried BC is cellulose $I_{\alpha}$-rich and never-dried BC is cellulose $I_{\beta}$-rich. It has been shown that cellulose $I_{\alpha}$ is more susceptible to acetylation compared to cellulose $I_{\beta}$. We postulate that it is this combination of more exposed $-\mathrm{OH}$ groups and the cellulose $\mathrm{I}_{\alpha}$ structure of freeze-dried BC which resulted in significantly higher bulk modification of the cellulose compared to never-dried $\mathrm{BC}$ under identical reaction conditions. However, the main question that we need to raise is: Why does never-dried BC, which was obtained by freeze-drying from an organic solvent is found to possess a cellulose $\mathrm{I}_{\beta}$ structure while it is well accepted that BC possesses a cellulose $\mathrm{I}_{\alpha}$ structure?

\section{Acknowledgements}

The authors would like to thank the UK Engineering and Physical Research Council (EPSRC) (EP/F032005/1) and Imperial College London for a Deputy Rector's award for KYL.

\section{References}

Barud HS, de Araujo AM, Santos DB, de Assuncao RMN, Meireles CS, Cerqueira DA, Rodrigues G, Ribeiro CA, Messaddeq Y, Ribeiro SJL (2008) Thermal behavior of cellulose acetate produced from homogeneous acetylation of bacterial cellulose. Thermochim Acta 471 (1-2):61-69

Blaker JJ, Lee KY, Bismarck A (2011) Hierarchical Composites Made Entirely from Renewable Resources. J Biobased Mater Bioenergy 5 (1):1-16 
Blaker JJ, Lee KY, Li XX, Menner A, Bismarck A (2009) Renewable nanocomposite polymer foams synthesized from Pickering emulsion templates. Green Chemistry 11 (9):13211326. doi:10.1039/b913740h

Brown AJ (1886) The chemical action of pure cultivations of bacterium aceti. Journal of the Chemical Society, Transations 49:172-187

Colombo EA, Immerguy EH (1970) Interaction of cellulose with organic liquids and vapors. Journal of Polymer Science Part C: Polymer Symposia 31 (1):137-156

Czaja W, Romanovicz D, Brown RM (2004) Structural Investigation of Microbial Cellulose Produced in Stationary and Agitated Culture. Cellulose 113-4 (403-411)

de Menezes AJ, Siqueira G, Curvelo AAS, Dufresne A (2009) Extrusion and characterization of functionalized cellulose whiskers reinforced polyethylene nanocomposites. Polymer 50 (19):4552-4563

Eichhorn SJ, Davies GR (2006) Modelling the crystalline deformation of native and regenerated cellulose. Cellulose 13 (3):291-307

Eichhorn SJ, Dufresne A, Aranguren M, Marcovich NE, Capadona JR, Rowan SJ, Weder C, Thielemans W, Roman M, Renneckar S, Gindl W, Veigel S, Keckes J, Yano H, Abe K, Nogi M, Nakagaito AN, Mangalam A, Simonsen J, Benight AS, Bismarck A, Berglund LA, Peijs T (2010) Review: current international research into cellulose nanofibres and nanocomposites. J Mater Sci 45 (1):1-33

Freire CSR, Silvestre AJD, Neto CP, Belgacem MN, Gandini A (2006) Controlled heterogeneous modification of cellulose fibers with fatty acids: Effect of reaction conditions on the extent of esterification and fiber properties. J Appl Polym Sci 100 (2):1093-1102

Gardner DJ, Oporto GS, Mills R, Samir M (2008) Adhesion and surface issues in cellulose and nanocellulose. J Adhes Sci Technol 22 (5-6):545-567

Habibi Y, Lucia LA, Rojas OJ (2010) Cellulose Nanocrystals: Chemistry, Self-Assembly, and Applications. Chem Rev 110 (6):3479-3500

Heinze T, Liebert T, Koschella A (2006) Esterification of Polysaccharides. Springer-Verlag, Berlin

Herrick FW, Casebier RL, Hamilton RI, Sandberg KR (1983) Microfibrillated cellulose: Morphology and accessibility. Journal of Applied Polymer Science: Applied Polymer Symposium 37:797-813

Horii F, Hirai A, Kitamaru R (1987a) Cp/Mas C-13 Nmr-Spectra of the Crystalline Components of Native Celluloses. Macromolecules 20 (9):2117-2120

Horii F, Yamamoto H, Kitamaru R, Tanahashi M, Higuchi T (1987b) Transformation of Native Cellulose Crystals Induced by Saturated Steam at High-Temperatures. Macromolecules 20 (11):2946-2949

Hsieh YC, Yano H, Nogi M, Eichhorn SJ (2008) An Estimation of the Young's Modulus of Bacterial Cellulose Filaments. Cellulose 15 (4):507-513

Ifuku S, Nogi M, Abe K, Handa K, Nakatsubo F, Yano H (2007) Surface modification of bacterial cellulose nanofibers for property enhancement of optically transparent composites: Dependence on acetyl-group DS. Biomacromolecules 8 (6):1973-1978. doi:10.1021/bm070113b

Ilharco LM, Garcia AR, daSilva JL, Ferreira LFV (1997) Infrared approach to the study of adsorption on cellulose: Influence of cellulose crystallinity on the adsorption of benzophenone. Langmuir 13 (15):4126-4132

Ishida O, Kim DY, Kuga S, Nishiyama Y, Brown RM (2004) Microfibrillar carbon from native cellulose. Cellulose 11 (3-4):475-480. doi:10.1023/B:CELL.0000046410.31007.0b 
Jin H, Nishiyama Y, Wada M, Kuga S (2004) Nanofibrillar cellulose aerogels. Colloids and Surfaces a-Physicochemical and Engineering Aspects 240 (1-3):63-67.

doi:10.1016/j.colsurfa.2004.03.007

Kim DY, Nishiyama Y, Kuga S (2002) Surface acetylation of bacterial cellulose. Cellulose 9 (34):361-367. doi:10.1023/a:1021140726936

Klemm D, Heublein B, Fink HP, Bohn A (2005) Cellulose: Fascinating Biopolymer and Sustainable Raw Material. Angewandte Chemie - International edition 44 (22):3358-3393

Klemm D, Schumann D, Kramer F, Hessler N, Koth D, Sultanova B (2009) Nanocellulose Materials - Different Cellulose, Different Functionality. Macromolecular Symposia 280:60-71

Kuga S, Kim DY, Nishiyama Y, Brown RM (2002) Nanofibrillar carbon from native cellulose. Molecular Crystals and Liquid Crystals 387:237-243. doi:10.1080/10587250290113510

Lee K-Y, Quero F, Blaker JJ, Hill CAS, Eichhorn SJ, Bismarck A (2011) Surface only modification of bacterial cellulose nanofibres with organic acids. Cellulose 18 (3):595605

Lee KY, Blaker JJ, Bismarck A (2009) Surface functionalisation of bacterial cellulose as the route to produce green polylactide nanocomposites with improved properties. Composites Science and Technology 69 (15-16):2724-2733

Ly EH, Bras J, Sadocco P, Belgacem MN, Dufresne A, Thielemans W (2010) Surface functionalization of cellulose by grafting oligoether chains. Mater Chem Phys 120 (23):438-445

Merchant MV (1957) A study of certain phenomena of the liquid exchange of water-swollen cellulose fibers and their subsequent drying from hydrocarbons. Lawrence College, Appleton, Wisconsin

Pommet M, Juntaro J, Heng JYY, Mantalaris A, Lee AF, Wilson K, Kalinka G, Shaffer MSP, Bismarck A (2008) Surface modification of natural fibers using bacteria: Depositing bacterial cellulose onto natural fibers to create hierarchical fiber reinforced nanocomposites. Biomacromolecules 9 (6):1643-1651

Reiling S, Brickmann J (1995) Theoretical Investigations on the Structure and PhysicalProperties of Cellulose. Macromol Theory Simul 4 (4):725-743

Sassi JF, Chanzy H (1995) Ultrastructural Aspects of the Acetylation of Cellulose. Cellulose 2 (2):111-127

Sassi JF, Tekely P, Chanzy H (2000) Relative susceptibility of the I-alpha and I-beta phases of cellulose towards acetylation. Cellulose 7 (2):119-132

Sczostak A (2009) Cotton Linters: An Alternative Cellulosic Raw Material. Macromolecular Symposia 280:45-53

Segal L, Creely JJ, Martin-Jr AE, Conrad CM (1959) An Emperical Method for Estimating the Degree of Crystallinity of Native Cellulose Using the X-Ray DIffractometer. Textile Research Journal 29 (10):786-794

Siro I, Plackett D (2010) Microfibrillated cellulose and new nanocomposite materials: a review. Cellulose 17 (3):459-494. doi:10.1007/s10570-010-9405-y

Spinu M, Dos Santos N, Le Moigne N, Navard P (2011) How does the never-dried state influence the swelling and dissolution of cellulose fibres in aqueous solvent? Cellulose 18 (2):247-256

Sugiyama J, Vuong R, Chanzy H (1991) Electron-Diffraction Study on the 2 Crystalline Phases Occurring in Native Cellulose from an Algal Cell-Wall. Macromolecules 24 (14):41684175 
Tingaut P, Zimmermann T, Lopez-Suevos F (2010) Synthesis and Characterization of Bionanocomposites with Tunable Properties from Poly(lactic acid) and Acetylated Microfibrillated Cellulose. Biomacromolecules 11 (2):454-464. doi:10.1021/bm901186u

Turbak AF, Snyder FW, Sandberg KR (1983) Microfibrillated cellulose, a new cellulose product: Properties, uses and commercial potential. Journal of Applied Polymer Science: Applied Polymer Symposium 37:459-494

Vanderhart DL, Atalla RH (1984) STUDIES OF MICROSTRUCTURE IN NATIVE CELLULOSES USING SOLID-STATE C-13 NMR. Macromolecules 17 (8):1465-1472. doi:10.1021/ma00138a009

Venkateswaran A, Riemen WP (1965) Experiments on the effect of ethylamine treatment on the crystallnity of cellulose. J Appl Polym Sci 9 (3):1139-1148

Wada M, Okano T, Sugiyama J (2001) Allomorphs of native crystalline cellulose I evaluated by two equatorial d-spacings. J Wood Sci 47 (2):124-128

Yin CY, Li JB, Xu Q, Peng Q, Liu YB, Shen XY (2007) Chemical modification of cotton cellulose in supercritical carbon dioxide: Synthesis and characterization of cellulose carbamate. Carbohydr Polym 67 (2):147-154. doi:10.1016/j.carbpol.2006.05.010 


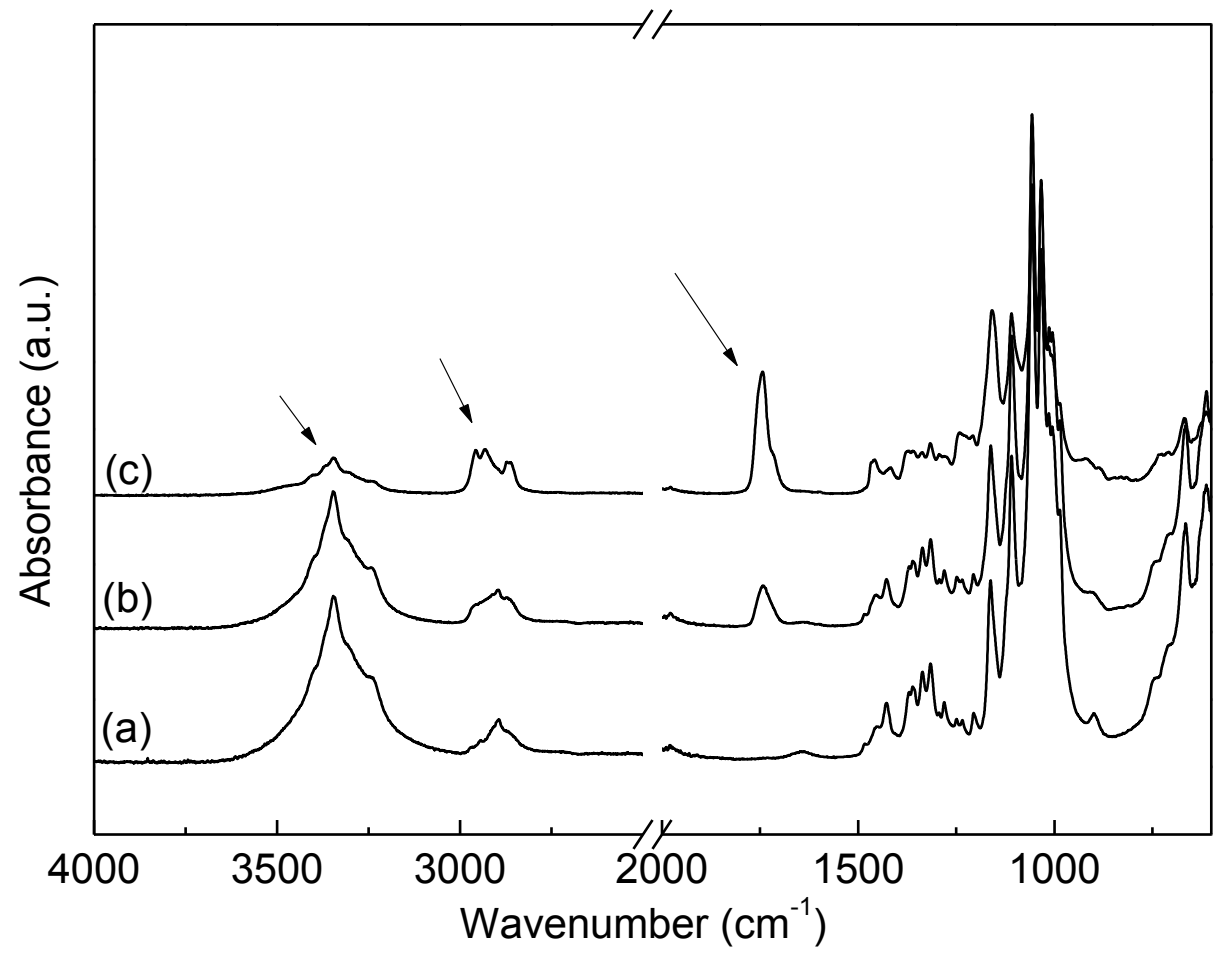

Fig. 1 ATR-IR spectra of neat and hexanoic acid modified BC. (a) Neat BC, (b) $\mathrm{C}_{6}$-NDBC and (c) $\mathrm{C}_{6}$-FDBC. 

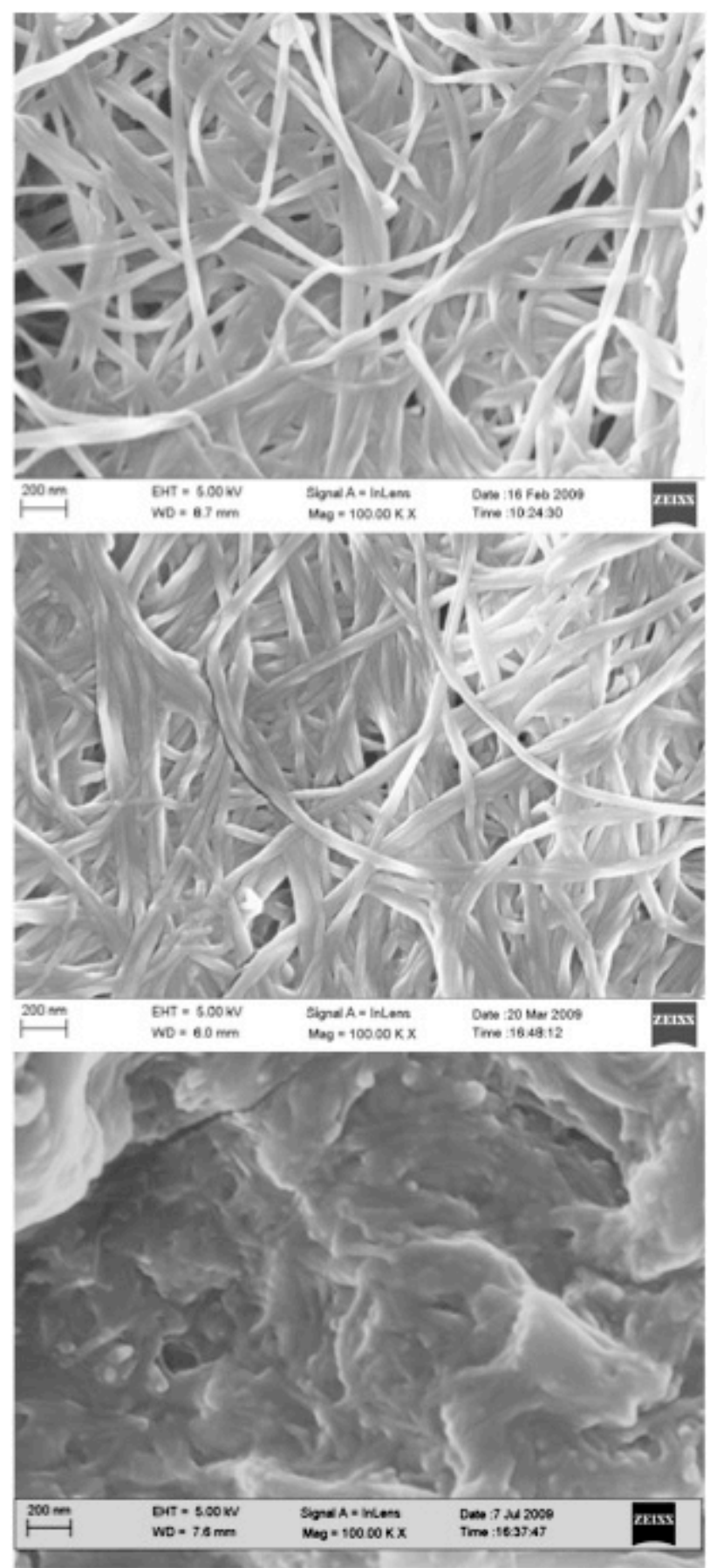

Fig. 2 Scanning electron micrographs showing the morphology of neat and modified BC. Top: Neat BC, middle: $\mathrm{C}_{6}$-NDBC and bottom: $\mathrm{C}_{6}$-FDBC. 


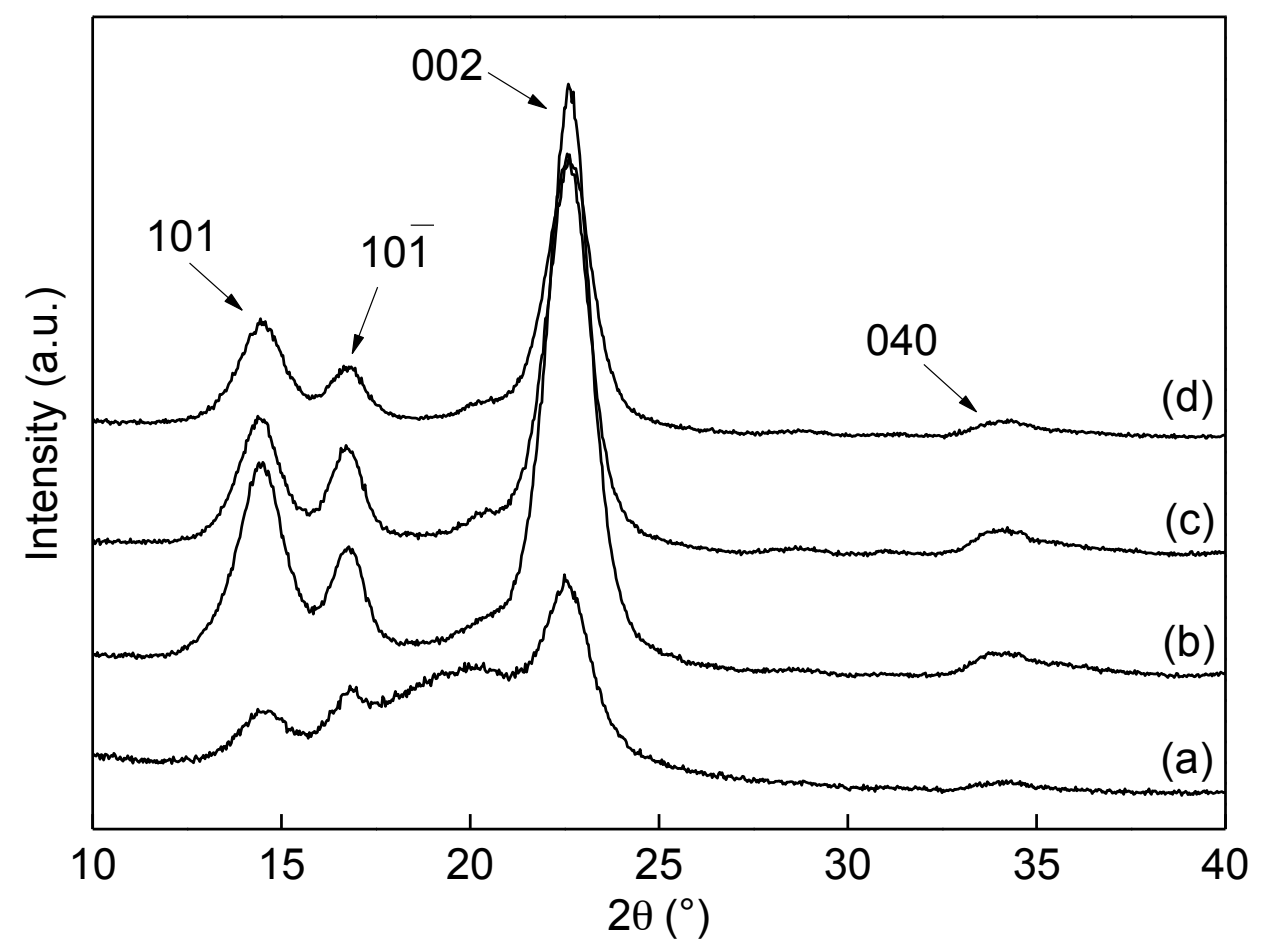

Fig. 3 XRD spectra of hexanoic acid modified BC. (a) $\mathrm{C}_{6}$-NDBC, (b) $\mathrm{C}_{6}$-FDBC, (c) never-dried BC and (d) freeze-dried $\mathrm{BC}$. 
Table 1: Degree of substitutions and crystallinity $\left(\chi_{c}\right)$ of hexanoic acid modified BC.

\begin{tabular}{lll}
\hline Sample & Degree of substitution & $\chi_{\mathbf{c}}(\mathbf{\%})$ \\
\hline $\mathrm{C}_{6}-\mathrm{NDBC}$ & $0.36 \pm 0.01$ & $91 \pm 3$ \\
$\mathrm{C}_{6}-\mathrm{FDBC}$ & $1.87 \pm 0.02$ & $53 \pm 4$ \\
\hline
\end{tabular}

Table 2: A table summarizing the estimated residual water content, accessible $-O H$ groups, specific surface area $(S)$, crystallinity $\left(\chi_{c}\right)$, d-spacings of the reflection at $14^{\circ}\left(d_{1}\right), 16^{\circ}\left(d_{2}\right)$ and the discriminant value between $\mathrm{I} \alpha$ and $\mathrm{I} \beta(\mathrm{Z})$, respectively of never-dried and freeze-dried $\mathrm{BC}$

\begin{tabular}{|c|c|c|c|c|c|c|c|}
\hline Types of BC & $\begin{array}{l}\text { Residual water } \\
\text { (mg/g cellulose) }\end{array}$ & $\begin{array}{l}\text { Accessible } \\
\text { OH group }^{\dagger}\end{array}$ & $S\left(m^{2} g^{-1}\right)$ & $\chi_{c}(\%)$ & $\begin{array}{l}d_{1} \\
(n m)\end{array}$ & $\begin{array}{l}d_{2} \\
(n m)\end{array}$ & $Z$ value \\
\hline Never-dried & $13 \pm 4$ & $1.12 \pm 0.04$ & $92.2 \pm 0.1$ & $90 \pm 4$ & 0.611 & 0.614 & -0.78 (I $\beta$-rich) \\
\hline Freeze-dried & $23 \pm 6$ & $1.24 \pm 0.01$ & $44.6 \pm 0.1$ & $89 \pm 3$ & 0.528 & 0.531 & 13.87 (Io-rich) \\
\hline
\end{tabular}

${ }^{\dagger}$ maximum value of 3 . 